\title{
Measuring the Cohesive Law in Mode I Loading of Eucalyptus globulus
}

\author{
Almudena Majano-Majano ${ }^{1, *}$, Antonio José Lara-Bocanegra ${ }^{1}{ }^{\circledR}$, José Xavier ${ }^{2} \mathbb{C}$ \\ and José Morais ${ }^{3}$ \\ 1 Department of Building Structures and Physics, ETS of Architecture, Universidad Politécnica de Madrid, \\ Avda Juan de Herrera 4, 28040 Madrid, Spain; antoniojose.lara@upm.es \\ 2 Department of Mechanical and Industrial Engineering, UNIDEMI, Faculty of Sciences and Technology, \\ New University of Lisbon, 2928-516 Caparica, Portugal; jmc.xavier@fct.unl.pt \\ 3 School of Science and Technology, CITAB, University of Trás-os-Montes e Alto Douro, 5001-801 Vila Real, \\ Portugal; jmorais@utad.pt \\ * Correspondence: almudena.majano@upm.es; Tel.: +34-910-675-016
}

Received: 1 December 2018; Accepted: 19 December 2018; Published: 21 December 2018

check for updates

\begin{abstract}
Assessing wood fracture behavior is essential in the design of structural timber elements and connections. This is particularly the case for connections with the possibility of brittle splitting failure. The numerical cohesive zone models that are used to simulate the fracture behavior of wood make it necessary to assume a cohesive law of the material that relates cohesive tractions and crack opening displacements ahead of the crack tip. This work addresses the determination of the fracture cohesive laws of Eucalyptus globulus, a hardwood species with great potential in timber engineering. This study centres on Mode I fracture loading for RL and TL crack propagation systems using Double Cantilever Beam tests. The Compliance-Based Beam Method is applied as the data reduction scheme in order to obtain the strain energy release rate from the load-displacement curves. The cohesive laws are determined by differentiating the relationship between strain energy release rate and crack tip opening displacement. The latter is measured by the digital image correlation technique. High strain energy release rates were obtained for this species, with no big differences between crack propagation systems. The difference between the crack systems is somewhat more pronounced in terms of maximum stress that determines the respective cohesive laws.
\end{abstract}

Keywords: Eucalyptus globulus; cohesive law; double cantilever beam; compliance-based beam method; mode I; digital image correlation

\section{Introduction}

Hardwood species are increasingly used for structural purposes, and this is shown, for instance, by in the development of new products with great impact in the European market. In particular, Eucalyptus globulus Labill is seen as a hardwood species with major potential in timber engineering, because of its high mechanical performance and durability, its aesthetic qualities, and the large stock of eucalyptus resources. This situation requires continuous research in different fields, where improvement of the drying process and the development of laminated products are two of the main ongoing research focuses [1-4].

Fracture characterization of wood is of essential importance, especially in the design of timber elements and connections in engineering structures [5,6]. Connections are most particularly some of the most critical parts, as they may lead to a dangerous situation in cases of brittle splitting failure produced by tension perpendicular to the grain. 
The current European design formulation for the prediction of the splitting failure of dowel connections loaded perpendicularly to the grain is only valid for softwood, and it is based on an energetic approach in the framework of Fracture Mechanics [7]. This formulation was originally calibrated using strain energy release rate values $\left(G_{\mathrm{I}}\right)$ that were obtained from experimental research reported in the literature [8]. Although proposals of other different analytical models considering $G_{I}$ as input material parameter have been compiled in the literature, [9] there is, at present, no general agreement between the results. This empirical research technique is time consuming and not-always cost-efficient. It may be more efficient to achieve these objectives through numerical simulations, which show advantages in terms of effectiveness with regard to time, cost, the exactitude of results, and the possibility of conducting parametric studies, e.g., [10,11].

Regarding numerical fracture models in wood, it must be noted that fracture behavior can be affected by nonlinear phenomena such as crack-bridging and micro-cracking along a fracture process zone (FPZ) ahead of the crack tip [12]. Accordingly, an appropriate fracture characterization can be formulated by using numerical cohesive zone models (CZM) based on nonlinear fracture mechanics in order to simulate the development of significant FPZ. In this way, the whole crack growth can be properly reproduced in a way that is closer to the actual behavior of the structure. The CZM were originally formulated for elastic-plastic fracture in metals [13,14]. Crack growth and damage phenomena in wood were firstly described in [15]. According to this and more specifically in Mode I tests, there is a linear and elastic relationship between load and displacements until the load approaches a critical value, where the first damage phenomena begin to appear in the specimen. When the maximum load is reached, the FPZ starts to develop and all of the additional displacements take place there, while the material outside the zone is elastically unloaded. In CZM, the degrading mechanisms in the FPZ are assumed to keep to a discrete line (or plane) represented by a cohesive law which defines material softening behavior and considers fracture energy evolution. This cohesive law relates the cohesive tractions and the crack tip opening displacements produced at the FPZ. Although different studies discuss the effect of cohesive stiffness and strength parameters, e.g., [16,17], the most common cohesive laws that are implemented in finite element codes are simplified into linear, bilinear, and exponential relationships. Suitable identification becomes relevant and remains an open problem, since there is no well-established methodology that makes this goal possible [18].

One group of methods applied in the literature for this purpose are the inverse methods $[19,20]$ whereby cohesive laws are obtained recursively through global load-displacement curves. The difference between the numerical and experimental curves is minimized by an optimization procedure that has the drawback that a cohesive law shape must be assumed a priori as this can significantly affect the fracture results [21]. Convergence to the minimum is not always guaranteed and sometimes demands sophisticated and time-consuming optimization algorithms.

Alternatively, a direct method has been proposed with the same aim but which is instead based on the relationship between strain energy release rate and crack tip opening displacements [22], which are determined independently by local measurements. This approach has the advantage of not requiring a priori cohesive law shape assumption.

In this work, the cohesive law in mode I of Eucalyptus globulus was directly identified using Double Cantilever Beam (DCB) tests, and it is the first such study carried out on this species. The strain energy release rate $\left(G_{I}\right)$ was explicitly derived from the load-displacement curves that were obtained in each test by applying the Compliance-Based Beam Method (CBBM). This method has the advantage of not requiring measurements of crack propagation during the test, which would be too difficult in practice given the material heterogeneity. An equivalent crack length $\left(a_{\mathrm{eq}}\right)$ was considered instead. The cohesive law, defined as the relationship between cohesive traction tension $\left(\sigma_{\mathrm{I}}\right)$ and crack tip opening displacement $\left(w_{\mathrm{I}}\right)$, was determined by differentiating the $G_{\mathrm{I}}-w_{\mathrm{I}}$ relationship and applying least-squares regression analysis. The $w_{\mathrm{I}}$-parameter was measured by digital image correlation (DIC) technique. This fracture behavior was studied for two crack propagation systems, RL and TL, where 
the first letter indicates the direction normal to the crack plane and the second letter refers to the crack propagation direction (Longitudinal, Radial, and Tangential).

\section{Materials and Methods}

\subsection{Raw Material}

Eucalyptus globulus Labill from Galicia, Northwest Spain, was used in this research. The boards were kiln-dried prior to sample preparation. It is worth noting that the boards were approximately knot-free (knot diameter less than 1/20 times board width), which is a characteristic feature of this species. Each board is identified with a reference number shown in Table 1. This table also includes the boards' densities $(\varrho)$ determined for a reference moisture content of $12 \%$, and the corresponding static longitudinal modulus of elasticity in the grain direction $\left(E_{\mathrm{L}}\right)$ resulting from edgewise bending tests under four-point loading according to EN 408:2011 [23].

Table 1. Density and elastic modulus of elasticity of Eucalyptus globulus boards.

\begin{tabular}{|c|c|c|}
\hline Board Ref & $\varrho\left(\mathrm{kg} / \mathrm{m}^{3}\right)$ & $E_{\mathrm{L}}(\mathrm{MPa})$ \\
\hline 140 & 781 & 19,863 \\
\hline 144 & 765 & 19,234 \\
\hline 161 & 867 & 19,658 \\
\hline 176 & 779 & 19,359 \\
\hline 189 & 748 & 19,114 \\
\hline 192 & 815 & 20,612 \\
\hline mean & 793 & 19,640 \\
\hline SD & 43 & 551 \\
\hline $\operatorname{CoV}(\%)$ & 5.4 & 2.8 \\
\hline
\end{tabular}

The orthotropic average values for the radial modulus of elasticity $E_{\mathrm{R}}=1820 \mathrm{MPa}$, the tangential modulus of elasticity $E_{\mathrm{T}}=821 \mathrm{MPa}$, the shear modulus of elasticity in the LR plane $G_{\mathrm{LR}}=1926 \mathrm{MPa}$, and the shear modulus of elasticity in the LT plane $G_{\mathrm{LT}}=969 \mathrm{MPa}$, are taken from [24] using Galician Eucalyptus globulus with a similar density to the boards used in this study. These parameters were obtained by compression tests coupled with a stereovision system (DIC 3D). DCB specimens were prepared from these boards according to the specifications shown in Section 2.3.

\subsection{Compliance-Based Beam Method (CBBM)}

The procedure applied to determine the cohesive law corresponds to a direct method that requires establishing the relationship between the strain energy release rate in mode I loading $\left(G_{\mathrm{I}}\right)$, the crack tip opening displacement $\left(w_{\mathrm{I}}\right)$, and the traction tension $\left(\sigma_{\mathrm{I}}\right)$, according to Equation (1).

$$
G_{\mathrm{I}}=\int_{0}^{w_{\mathrm{I}}} \sigma_{\mathrm{I}}\left(\bar{w}_{\mathrm{I}}\right) \mathrm{d} \bar{w}_{\mathrm{I}}
$$

The cohesive law in mode I, defined as $\sigma_{\mathrm{I}}=\mathrm{f}\left(w_{\mathrm{I}}\right)$, can be then determined by differentiating Equation (1), as follows:

$$
\sigma_{\mathrm{I}}\left(w_{\mathrm{I}}\right)=\frac{\partial G_{\mathrm{I}}}{\partial w_{\mathrm{I}}}
$$

This requires the accurate measurement of $G_{\mathrm{I}}$ evolution as a function of $w_{\mathrm{I}}$ in the course of an experimental fracture test (in this case a DCB test, see details in Section 2.3). The classical data reduction schemes used for this purpose are based on beam theory or compliance calibration and require crack length (a) measuring during testing [25]. However, the fracture process zone (FPZ) ahead of the crack tip in wood involves toughening mechanisms, such as microcracking, crack-branching, or fiber-bridging, hindering the identification of the crack tip and therefore also the $a$-measurement. 
To overcome this problem, the Compliance Based Beam method (CBBM) $[20,26]$ is shown to be a suitable alternative. It is based on Timoshenko beam theory and it introduces the concept of an equivalent crack length $\left(a_{\mathrm{eq}}\right)$, accounting for the FPZ effect given by $a_{\mathrm{eq}}=a+\Delta+\Delta a_{\mathrm{FPZ}}$. Accordingly, compliance for a DCB specimen during crack propagation can be written as

$$
C=\frac{8 a_{\mathrm{eq}}{ }^{3}}{E_{f} B h^{3}}+\frac{12 a_{\mathrm{eq}}}{5 B h G_{\mathrm{LR}}}
$$

where $G_{\mathrm{LR}}$ is the shear modulus in the LR plane; $B$ and $h$ the specimen dimensions; and, $E_{f}$ the corrected flexural modulus (instead of $E_{\mathrm{L}}$ ) to take into account the cross-section rotation effects at the crack tip during testing and local stress concentrations. $E_{f}$ can be estimated from Equation (4) when considering the initial compliance $\left(C_{0}\right)$ and a corrected initial crack length $\left(a_{0}+\Delta\right)$

$$
E_{f}=\left(C_{0}-\frac{12\left(a_{0}+\Delta\right)}{5 B h G_{\mathrm{LR}}}\right)^{-1} \frac{8\left(a_{0}+\Delta\right)^{3}}{B h^{3}}
$$

where $\Delta$ represents the Williams correction term given by [27] in the form:

$$
\begin{gathered}
\Delta=h \sqrt{\frac{E_{f}}{11 G_{\mathrm{LR}}}\left[3-2\left(\frac{\Gamma}{1+\Gamma}\right)^{2}\right]} \\
\Gamma=1.18 \frac{\sqrt{E_{f} E_{\mathrm{R}}}}{G_{\mathrm{LR}}}
\end{gathered}
$$

An iterative process can be used to solve Equations (4)-(6) until a converged value of $E_{f}$ is reached. It must be noted that $E_{\mathrm{T}}$ and $G_{\mathrm{LT}}$ values should be used instead of $E_{\mathrm{R}}$ and $G_{\mathrm{LR}}$ in Equations (3)-(7) when the TL crack propagation system is considered.

The equivalent crack length, $a_{\mathrm{eq}}$, that meets the specimen compliance recorded during propagation is evaluated from a polynomial function solved with Matlab ${ }^{\circledR}$ (Mathworks, Madrid, Spain), according to [20].

Let us consider the Irwin-Kies equation [28]

$$
G_{\mathrm{I}}=\frac{P^{2}}{2 B} \frac{\mathrm{d} C}{\mathrm{~d} a}
$$

the strain energy release rate in mode $I\left(G_{I}\right)$ is obtained by combining Equations (3) and (7). It represents the resistance curve ( $R$-curve) of the material to the crack growth.

$$
G_{\mathrm{I}}=\frac{6 P^{2}}{B^{2} h}\left(\frac{2 a_{\mathrm{eq}}^{2}}{E_{f} h^{2}}+\frac{1}{5 G_{\mathrm{LR}}}\right)
$$

The CBBM method has the definitive advantage of only requiring the experimental load-displacement $(P-\delta)$ curve to derive the evolution of $G_{I}$ without crack length monitoring, making it less sensitive to experimental errors. The $G_{I}$ is then correlated with crack tip opening displacement in mode I $\left(w_{\mathrm{I}}\right)$, measured by the digital image correlation (DIC) technique during the test (see details in Section 2.3) and its derivative yields in the cohesive law expressed in Equation (2). It is therefore important to accurately evaluate the $G_{\mathrm{I}}=\mathrm{f}\left(w_{\mathrm{I}}\right)$ relationship. This was performed in two ways for further comparison and discussion: (a) a smoothing spline using Matlab ${ }^{\circledR}$ was adjusted to the experimental curve in order to soften the noise before differentiation; (b) the $G_{\mathrm{I}}-w_{\mathrm{I}}$ data were fitted, in the least-square sense, by a continuous approximation function (logistic function), as follows,

$$
\mathrm{G}_{\mathrm{I}}=\frac{A_{1}-A_{2}}{1+\left(w_{\mathrm{I}} / w_{\mathrm{I}, 0}\right)^{p}}+A_{2}
$$


where $A_{1}, A_{2}, p$, and $w_{\mathrm{I}, 0}$ are constants determined by regression analysis. Although this function has no particular physical meaning, it is simply a tool for the analytical differentiation that is required to obtain the cohesive law. The $A_{2}$ parameter must provide an estimation of the critical strain release, as

$$
A_{2}=\lim _{w_{\mathrm{I}} \rightarrow \infty} G_{\mathrm{I}}=G_{\mathrm{Ic}}
$$

The direct approach presented in this data reduction scheme can be potentially extended to other fracture modes, including mode II by means of the end notched flexure (ENF) test [29,30].

\subsection{Double Cantilever Beam (DCB) Test Coupled with Digital Image Correlation}

Thirteen DCB specimens that were oriented along the RL crack propagation system and fourteen oriented along the TL system were prepared for fracture tests. The first letter indicates the loading direction (Radial and Tangential, respectively) and the second letter refers to the crack propagation direction (Longitudinal). The DCB specimens consist of a rectangular beam with $L_{1} \times 2 h \times B \mathrm{~mm}$ $(250 \mathrm{~mm} \times 20 \mathrm{~mm} \times 20 \mathrm{~mm})$ nominal dimension, as schematically shown in Figure 1 . A mid-height pre-cracked surface of $100 \mathrm{~mm}$ in length and $1 \mathrm{~mm}$ thickness was initially performed. This initial notch was then lengthened a few millimeters with a band saw in order to guarantee a sharp initial crack. The actual $a_{0}$ value for each specimen was measured after testing. A symmetrical pair of $3 \mathrm{~mm}$ diameter holes were drilled at $10 \mathrm{~mm}$ from the specimen end, where the load $(P)$ perpendicular to the pre-cracked surface was applied. The applied load was transferred to the specimen by means of two $3 \mathrm{~mm}$ diameter steel pins that were inserted into the holes.

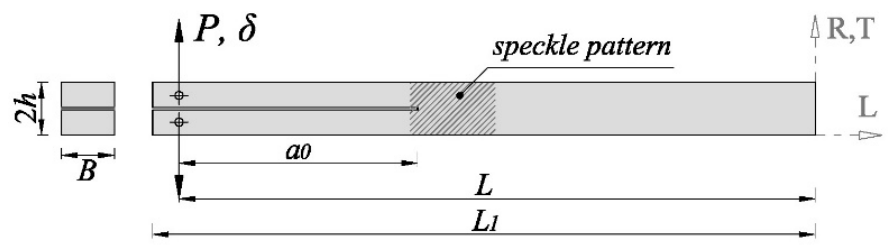

Figure 1. Double Cantilever Beam (DCB) specimen geometry.

Prior to testing, the specimens were conditioned at $20{ }^{\circ} \mathrm{C}$ and $65 \%$ relative humidity until equilibrium moisture content was reached. The mean value of moisture content was approximately $11 \%$.

The fracture tests were carried out using an INSTRON 1125 universal testing machine (Instron, Barcelona, Spain) with a load cell having a maximum capacity of $5 \mathrm{kN}$ and $50 \mathrm{~N} / \mathrm{V}$ gain. Specimens were loaded under $3 \mathrm{~mm} / \mathrm{min}$ displacement control.

Crack mouth opening displacement was recorded using the optical system ARAMIS DIC-2D (GOM mbH, Braunschweig, Germany) [31,32] (Figure 2). This is a non-contact system that applies the principles of digital image correlation (DIC). This technique shows clear advantages in comparison with traditional measurement methods since it makes it possible to measure the deformation field of a whole specimen area, providing more robust results. It is composed of an eight-bit charge-coupled device (CCD) camera with a telecentric lens that was mounted on a translation bar for fine aligning of the optical axis with regard to the planar specimen surface. The specimens were illuminated by two cold light sources incorporated in the measuring device. A speckled pattern with black ink on a white matte surface is applied to the specimen by an airbrush IWATA, model CM-B (Anesta Iwata Iberica SL, Barcelona, Spain), so that proper granulometry contrast and isotropy at the magnification scale is ensured. The region of interest is focused on the area just in front of the crack tip, where the crack starts to propagate. The different components of the optical system and the measuring parameters selected for this work are compiled in Table 2 . Complete $P-\delta$ curves were obtained in all tests with an acquisition rate of $5 \mathrm{~Hz}$, while the acquisition of images from DIC was made with $1 \mathrm{~Hz}$ frequency. 

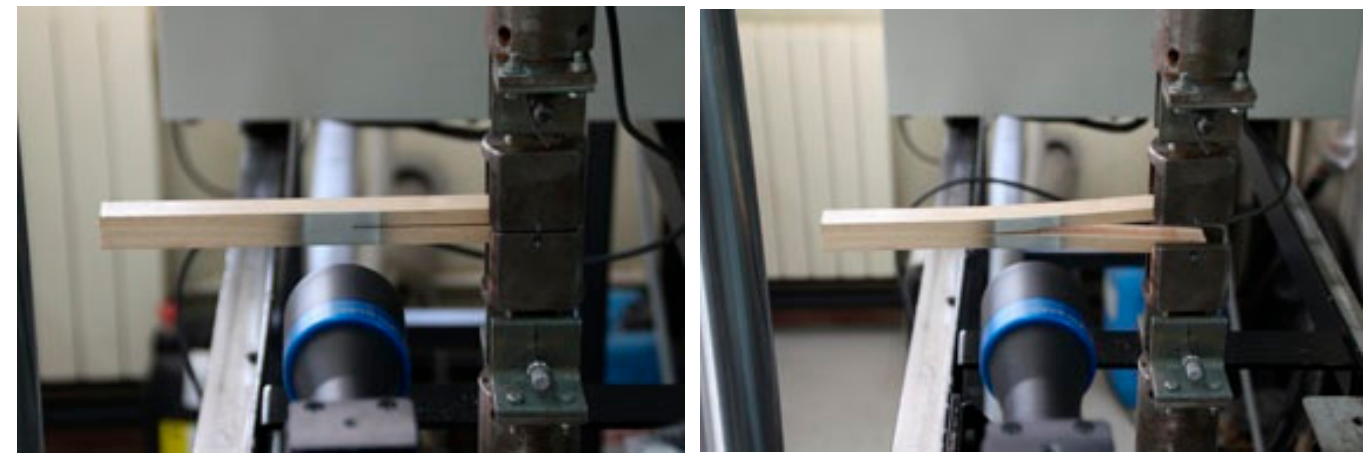

Figure 2. DCB test set-up coupled with digital image correlation (DIC).

Table 2. Components of the optical system and DIC measuring parameters.

\begin{tabular}{|c|c|}
\hline CCD Camera & Settings \\
\hline Model & Baumer Optronic FWX20 (8 bits, $1624 \times 1236$ pixels, $4.4 \mu \mathrm{m} /$ pixel) \\
\hline Shutter time & $0.7 \mathrm{~ms}$ \\
\hline Acquisition frequency & $1 \mathrm{~Hz}$ \\
\hline \multicolumn{2}{|l|}{ Lens } \\
\hline Model & Opto Engineering Telecentric lens TC 2336 \\
\hline Magnification & $0.243 \pm 3 \%$ \\
\hline Field of view $\left(1 / 1.8^{\prime \prime}\right)$ & $29.3 \times 22.1 \mathrm{~mm}^{2}$ \\
\hline Working distance & $103.5 \pm 3 \mathrm{~mm}$ \\
\hline Working F-number & $f / 8$ \\
\hline Field depth & $11 \mathrm{~mm}$ \\
\hline Conversion factor & $0.018 \mathrm{~mm} /$ pixel \\
\hline Lighting & Raylux 25 white-light LED \\
\hline \multicolumn{2}{|l|}{ DIC measurements } \\
\hline Subset size & $15 \times 15$ pixel $^{2}\left(0.270 \times 0.270 \mathrm{~mm}^{2}\right)$ \\
\hline Subset step & $13 \times 13$ pixel $^{2}\left(0.234 \times 0.234 \mathrm{~mm}^{2}\right)$ \\
\hline Resolution & $1-2 \times 10^{-2}$ pixel $(0.18 \times 0.36 \mu \mathrm{m})$ \\
\hline
\end{tabular}

The crack tip opening displacement in mode I $\left(w_{\mathrm{I}}\right)$ was obtained by post-processing the displacements monitored by DIC. The initial crack length was firstly identified in the undeformed image. The relative displacement between a pair of subsets selected close to the crack tip is evaluated afterwards. The value of $w_{\text {I }}$ is calculated as the Eucledian norm, as shown in Equation (9) $[33,34]$.

$$
w_{\mathrm{I}}=\left\|w_{\mathrm{I}}^{+}-w_{\mathrm{I}}^{-}\right\|
$$

where $w_{\mathrm{I}}^{+}$and $w_{\mathrm{I}}^{-}$are the displacement components in the direction perpendicular to the crack propagation associated to the upper and the lower cracked surface, respectively. This approach has the limitation of defining the cohesive law based on surface measurements, which may not be fully representative of the crack front over the volume of the FPZ. Current research interests have been expanded to the experimental observation of the volumetric crack front ahead of the crack tip by X-ray computed tomography $[35,36]$ and exploring paths, which includes digital volume correlation, for the quantitative extraction of relevant mechanical [37,38] and fracture parameters [39].

\section{Results and Discussion}

\subsection{Resistance Curve from CBBM}

The load-displacement curves obtained from the DCB specimens for RL ant TL crack propagation systems are shown in Figure 3. 

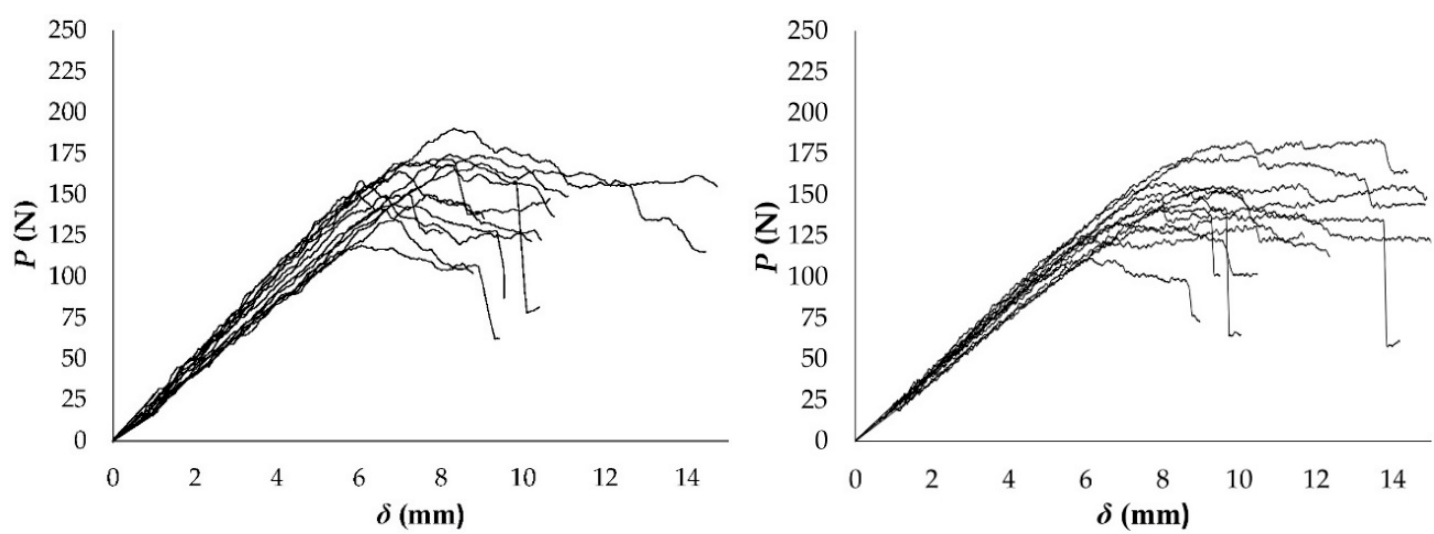

Figure 3. $P$ - $\delta$ curves from DCB test in RL (left) and TL (right) propagation systems.

Both groups of $P-\delta$ curves show quite consistent results with variation typical of wood. The non-linear behaviour that was observed before the curves peak reveals that a non-negligible FPZ develops ahead of the crack tip. This phenomenon is characteristic of quasi-brittle materials, like wood and results in micro-cracking and fiber bridging, as confirmed by the macroscopic image in Figure 4 . These observations are in agreement with other authors' research in wood $[19,25]$. This fact supports the difficulties in measuring the crack length during testing using conventional techniques and the convenience of applying the alternative CBBM method, when considering an equivalent crack length.
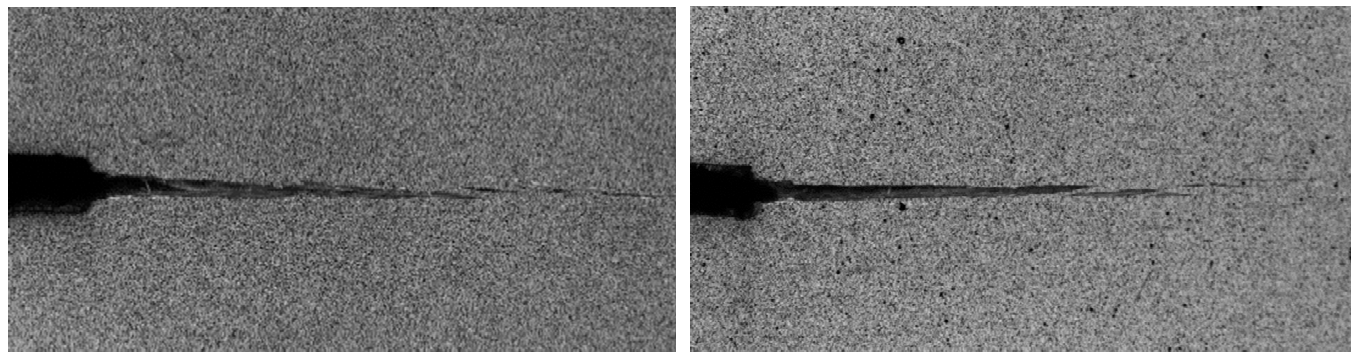

Figure 4. Macroscopic images of crack propagation: “DCB 176-3 RL” (left); “DCB 192-2 TL” (right).

The maximum loads that were attained in the tests are shown in Tables 3 and 4 for RL and TL crack propagations systems, respectively. The mean value from TL specimens is slightly lower than the one obtained from RL, but all of the values vary within a similar range. This means that the high proportion of radially oriented rays acting as reinforcement in this direction typical of hardwoods, like beech and ash [40], is not shown so pronouncedly in eucalyptus. However, microstructural constrictions may act in both directions. In most specimens, the decrease in load did not occur suddenly after reaching the peak load, as it arose gradually after a considerable increase in displacements, displaying an uneven behavior, due, once again, to the complex structure of wood $[26,40]$.

The initial compliance $C_{0}$ is calculated using Matlab ${ }^{\circledR}$, as this is the result that provides the maximum $R^{2}$ in every $P-\delta$ curve. A representative example of a DCB specimen is shown in Figure 5. The $C_{0}$ values resulting from all the tests are also included in Tables 3 and 4 for both crack propagation systems. There are minor quantitative differences between both orientations, while scatter is within the expected range for wood. 
Table 3. Fracture energy obtained from DCB specimens oriented in RL by means of Compliance-Based Beam Method (CBBM).

\begin{tabular}{cccccc}
\hline Specimen Ref & $\boldsymbol{E}_{\boldsymbol{f}}(\mathbf{M P a})$ & $\boldsymbol{P}_{\max }(\mathbf{N})$ & $\boldsymbol{C}_{\mathbf{0}}(\mathbf{m m} / \mathbf{N})$ & $G_{\mathbf{I}, \mathbf{P m a x}}(\mathbf{N} / \mathbf{m m})$ & $G_{\mathbf{I c}}(\mathbf{N} / \mathbf{m m})$ \\
\hline 140-1-RL & 14,250 & 191.70 & 0.042 & 1.07 & 1.01 \\
144-1-RL & 15,203 & 173.00 & 0.040 & 0.81 & 0.84 \\
144-2-RL & 13,254 & 123.08 & 0.048 & 0.52 & 0.48 \\
161-1-RL & 12,266 & 172.35 & 0.047 & 0.97 & 0.95 \\
161-3-RL & 14,593 & 176.29 & 0.039 & 0.85 & 0.85 \\
176-1-RL & 14,557 & 151.70 & 0.042 & 0.65 & 0.61 \\
176-2-RL & 12,335 & 156.59 & 0.049 & 0.82 & 0.76 \\
176-3-RL & 11,577 & 183.95 & 0.048 & 1.10 & 1.02 \\
189-1-RL & 15,087 & 168.16 & 0.039 & 0.75 & 0.70 \\
189-2-RL & 12,293 & 177.06 & 0.045 & 0.95 & 0.92 \\
192-1-RL & 16,707 & 162.01 & 0.038 & 0.65 & 0.63 \\
192-2-RL & 14,399 & 147.76 & 0.044 & 0.70 & 0.65 \\
192-3-RL & 16,103 & 153.99 & 0.038 & 0.56 & 0.57 \\
\hline Mean & 14,048 & 164.43 & 0.043 & 0.80 & 0.77 \\
SD & 1590 & 18.03 & 0.004 & 0.19 & 0.18 \\
CoV (\%) & 11 & 11 & 10 & 23 & 23 \\
\hline
\end{tabular}

Table 4. Fracture energy obtained from DCB specimens oriented in TL by means of CBBM.

\begin{tabular}{|c|c|c|c|c|c|}
\hline Specimen Ref & $E_{f}(\mathrm{MPa})$ & $P_{\max }(\mathrm{N})$ & $C_{0}(\mathrm{~mm} / \mathrm{N})$ & $G_{I, P \max }(\mathrm{N} / \mathrm{mm})$ & $G_{\text {Ic }}(\mathrm{N} / \mathrm{mm})$ \\
\hline 140-1-TL & 14,491 & 182.31 & 0.046 & 1.03 & 0.96 \\
\hline 140-2-TL & 11,295 & 157.74 & 0.055 & 0.94 & 0.89 \\
\hline 144-1-TL & 14,080 & 154.80 & 0.049 & 0.75 & 0.72 \\
\hline 161-1-TL & 12,742 & 188.28 & 0.049 & 1.28 & 1.09 \\
\hline $176-1-\mathrm{TL}$ & 12,466 & 146.01 & 0.054 & 0.84 & 0.82 \\
\hline 176-2-TL & 13,516 & 160.37 & 0.049 & 0.93 & 0.84 \\
\hline 176-3-TL & 12,103 & 147.33 & 0.053 & 0.81 & 0.78 \\
\hline 189-1-TL & 12,482 & 162.12 & 0.050 & 0.85 & 0.84 \\
\hline 189-2-TL & 14,087 & 160.69 & 0.046 & 0.77 & 0.76 \\
\hline 192-1-TL & 15,538 & 126.49 & 0.044 & 0.45 & 0.47 \\
\hline 192-2-TL & 14,421 & 139.78 & 0.048 & 0.61 & 0.62 \\
\hline 192-3-TL & 13,220 & 114.81 & 0.050 & 0.47 & 0.44 \\
\hline Mean & 13,370 & 153.39 & 0.049 & 0.81 & 0.77 \\
\hline SD & 1207 & 20.76 & 0.003 & 0.23 & 0.19 \\
\hline $\mathrm{CoV}(\%)$ & 9 & 14 & 7 & 29 & 24 \\
\hline
\end{tabular}
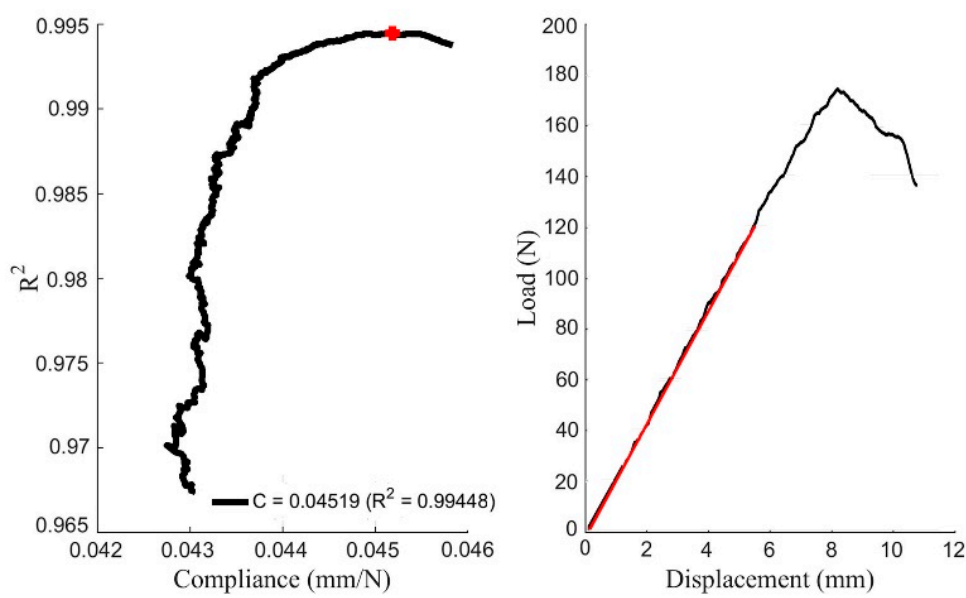

Figure 5. Representative curves for initial compliance determination. 
The $R$-curves that were obtained from DCB tests in RL and TL crack propagation systems were evaluated by applying the CBBM and they are shown in Figure 6. From them, following an initial rising domain characterized by the development of the FPZ (corresponding to the non-linearity beginning in $P-\delta$ curve), resistance to crack growth tends to a horizontal asymptote, despite the noise in the measurements, which defines the value of critical strain energy release rate $\left(G_{\mathrm{IC}}\right)$ and it represents the material's toughness to crack-growth.
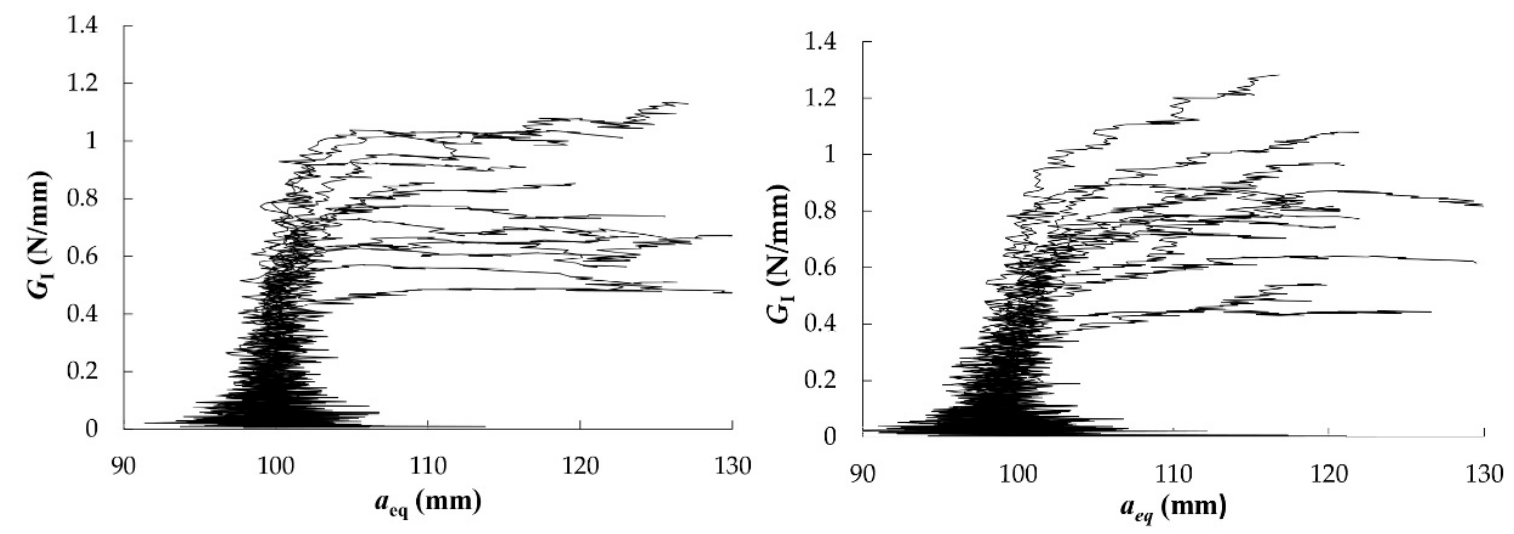

Figure 6. $R$-curves from DCB test in RL (left) and TL (right) propagation systems.

In this research, most of the specimens had plateaus for a given crack extent, which means that the FPZ has been completely developed. Therefore, the fracture energy could be determined as a mean value over the horizontal domain of the curves. In cases where the $R$-curve did not show a clear plateau, the strain energy release rate corresponding to the maximum load $\left(G_{\mathrm{I}, \mathrm{Pmax}}\right)$ could be assumed as critical strain energy release rate. Both values are reported in Tables 3 and 4 , together with the maximum load reached in the tests, the corrected flexural modulus of elasticity from every specimen and the initial compliance. The last three values are input parameters in the CBBM formulation detailed in Section 2.2. The wide dispersion of $R$-curves may be due to local variability of wood microstructure at the crack tip among the specimens, e.g., earlywood and latewood [26].

The mean $G_{\text {Ic }}$ values that were obtained from both crack propagation systems were found to be the same: $0.77 \mathrm{~N} / \mathrm{mm}$. This value is considerably higher than that for other species. In particular, DCB specimens of Pinus pinaster gave a mean $G_{\text {Ic }}$ value of $0.31 \mathrm{~N} / \mathrm{mm}$ when applying the same data reduction method in [25]. Eucalyptus globulus also displays higher fracture energy than other hardwood species. For instance, average $G_{\mathrm{f}}$ values of 0.48 and $0.40 \mathrm{~N} / \mathrm{mm}$ were obtained for beech and ash, respectively, in previous work by the author [40].

As the differences between $G_{I c}$ and $G_{I, P m a x}$ were minimal (see Tables 3 and 4), the latter can be taken as a practical measure of mode I critical strain energy release rate.

\subsection{Cohesive Law}

$G_{I}$ evolution was correlated with the crack tip opening displacement (CTOD) values that were provided by DIC during testing in order to obtain the cohesive law in mode I. Normal and transverse CTOD with respect to the crack plane were determined. Representative normal and transverse CTOD- $\delta$ curves are shown in Figure 7. As can be seen, CTOD in mode II ( $\left.w_{\text {III }}\right)$ was found to be negligible in DCB mode I tests. 

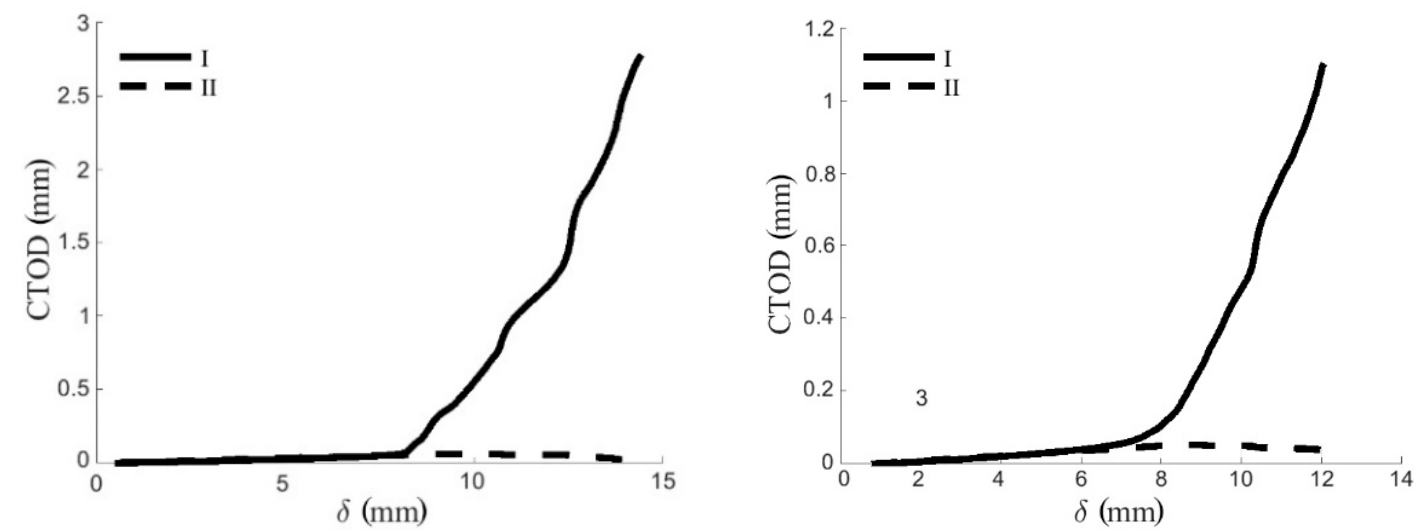

Figure 7. Normal and transverse crack tip opening displacements (CTOD) measured by DIC from a representative DCB test in RL (left) and TL (right) crack propagation systems.

Characteristic $G_{\mathrm{I}}-w_{\mathrm{I}}$ curves were then obtained, as shown in Figures 8 and 9.
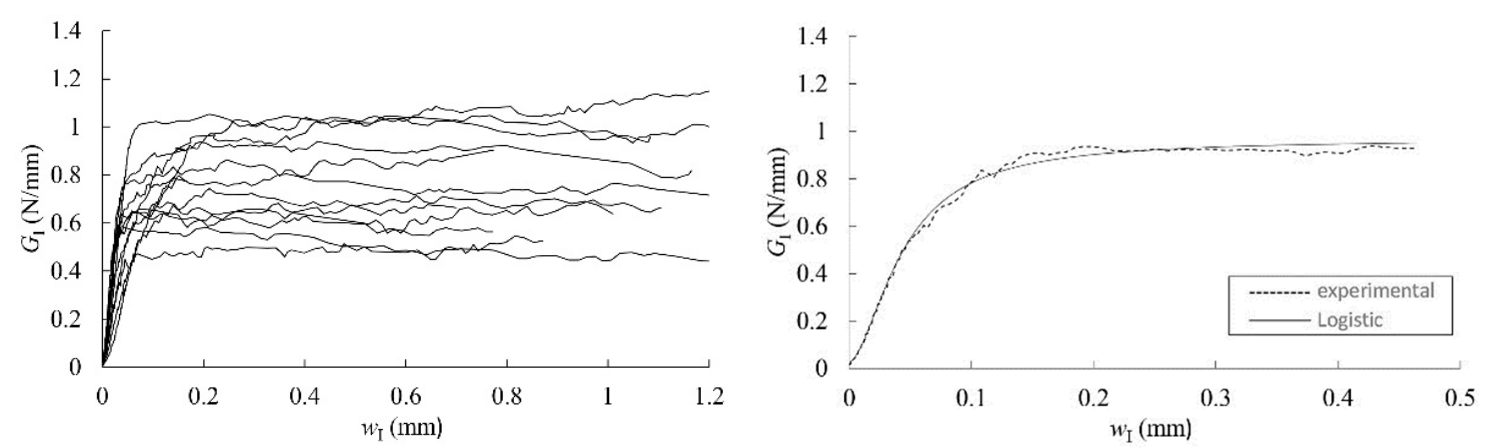

Figure 8. Characteristic $G_{\mathrm{I}}-w_{\mathrm{I}}$ curves in RL (left); experimental $G_{\mathrm{I}}-w_{\mathrm{I}}$ curve of "189-2-RL" specimen and least-square regression with the logistic function (right).
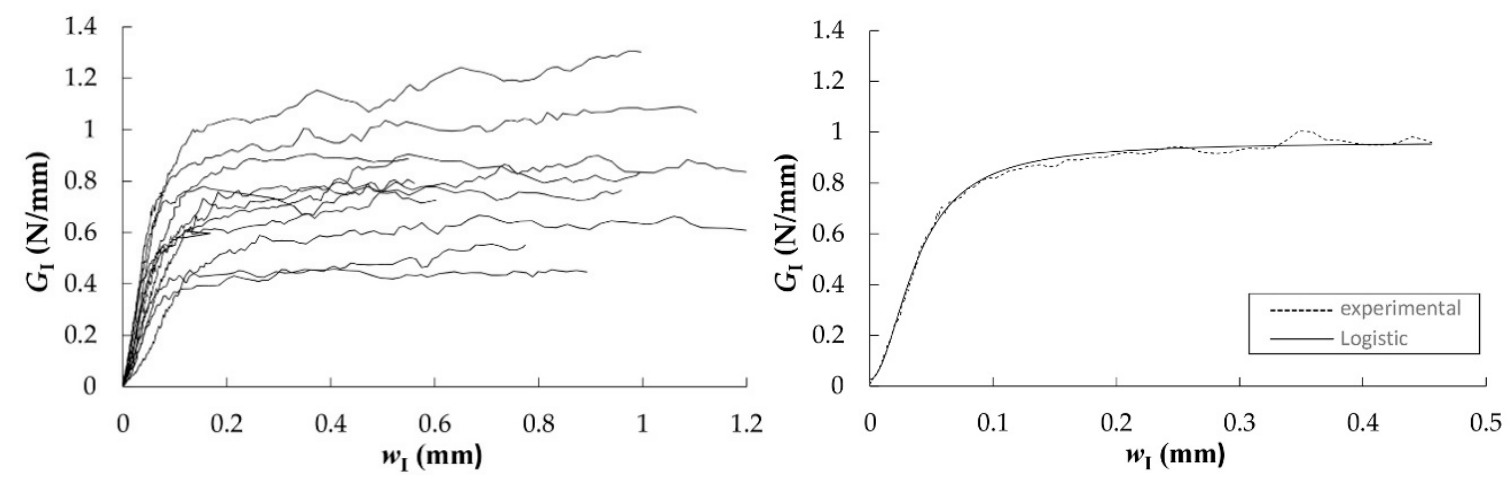

Figure 9. Characteristic $G_{\mathrm{I}}-w_{\mathrm{I}}$ curves in TL (left); experimental $G_{\mathrm{I}}-w_{\mathrm{I}}$ curve of "140-1-TL" specimen and least-square regression with the logistic function (right).

The cohesive law for each specimen was finally determined by fitting a logistic function to the experimental data, as shown in Figure 10. The parameters corresponding to the logistic function expressed in Equation (9) $\left(A_{1}, A_{2}, p\right.$, and $\left.w_{\mathrm{I} 0}\right)$, the area circumscribed by the cohesive laws $\left(G_{\mathrm{law}, \mathrm{I}}\right)$, the maximum stress $\left(\sigma_{\mathrm{I}, \mathrm{u}}\right)$, and the relative displacements $\left(w_{\mathrm{Iu}}\right.$ and $\left.w_{\mathrm{Ic}}\right)$ are all included in Tables 5 and 6 for RL and TL crack propagation systems, respectively. 

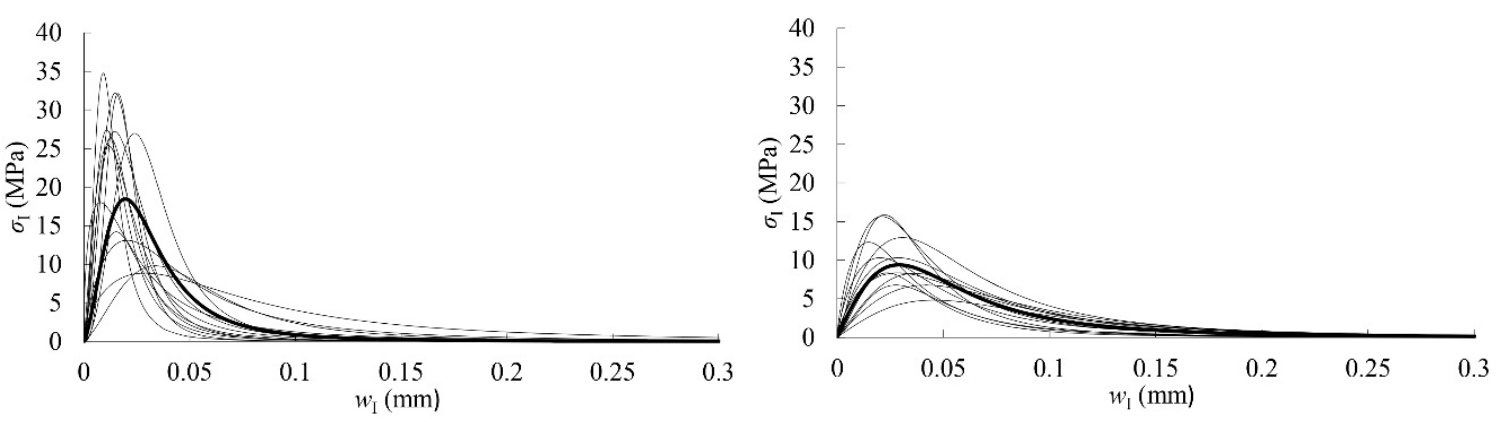

Figure 10. Cohesive laws in RL (left) and TL (right). Mean cohesive law is highlighted in bold.

Table 5. Logistic function parameters $\left(A_{1}, A_{2}, p\right.$, and $\left.w_{\mathrm{IO}}\right)$, maximum stress $\left(\sigma_{\mathrm{Iu}}\right)$ and relative displacement $\left(w_{\mathrm{Iu}}\right)$, as determined by CBBM equations, from specimens with the RL crack system.

\begin{tabular}{cccccccc}
\hline Ref & $\begin{array}{c}\boldsymbol{A}_{\mathbf{1}} \\
(\mathbf{N} / \mathbf{m m})\end{array}$ & $\begin{array}{c}\boldsymbol{A}_{\mathbf{2}} \\
(\mathbf{N} / \mathbf{m m})\end{array}$ & $\boldsymbol{p} \mathbf{( - )}$ & $\begin{array}{c}\boldsymbol{w}_{\mathbf{I 0}} \\
(\mathbf{m m})\end{array}$ & $\begin{array}{c}G_{\mathbf{l a w}, \mathbf{I}} \\
\mathbf{( N / m m )}\end{array}$ & $\begin{array}{c}\sigma_{\text {Iu }} \\
\mathbf{( M P a})\end{array}$ & $\begin{array}{c}\boldsymbol{w}_{\text {Iu }} \\
(\mathbf{m m})\end{array}$ \\
\hline 140-1-RL & 0.044 & 1.04 & 2.93 & 0.030 & 1.00 & 26.94 & 0.024 \\
144-1-RL & 0.039 & 0.82 & 2.80 & 0.019 & 0.78 & 32.21 & 0.015 \\
144-2-RL & 0.024 & 0.49 & 2.30 & 0.023 & 0.46 & 14.21 & 0.015 \\
161-1-RL & 0.029 & 0.93 & 2.20 & 0.023 & 0.91 & 27.19 & 0.014 \\
161-3-RL & 0.016 & 0.78 & 2.02 & 0.020 & 0.75 & 25.39 & 0.011 \\
176-1-RL & 0.026 & 0.67 & 2.46 & 0.018 & 0.64 & 26.35 & 0.013 \\
176-2-RL & 0.010 & 0.78 & 1.42 & 0.026 & 0.76 & 18.00 & 0.008 \\
176-3-RL & 0.025 & 1.10 & 1.58 & 0.074 & 1.05 & 8.86 & 0.029 \\
189-1-RL & 0.019 & 0.73 & 2.29 & 0.051 & 0.70 & 9.79 & 0.034 \\
189-2-RL & 0.028 & 0.97 & 1.72 & 0.044 & 0.92 & 13.11 & 0.020 \\
192-1-RL & 0.024 & 0.63 & 2.37 & 0.016 & 0.61 & 27.41 & 0.011 \\
192-2-RL & 0.043 & 0.66 & 3.60 & 0.019 & 0.62 & 32.11 & 0.016 \\
192-3-RL & 0.035 & 0.58 & 2.69 & 0.012 & 0.55 & 34.78 & 0.009 \\
\hline Mean & 0.028 & 0.78 & 2.34 & 0.029 & 0.75 & 22.80 & 0.017 \\
SD & 0.010 & 0.18 & 0.59 & 0.018 & 0.18 & 8.90 & 0.008 \\
CoV (\%) & 37 & 23 & 25 & 61 & 24 & 39 & 47 \\
\hline
\end{tabular}

Table 6. Logistic function parameters $\left(A_{1}, A_{2}, p\right.$, and $\left.w_{\mathrm{I} 0}\right)$, maximum stress $\left(\sigma_{\mathrm{Iu}}\right)$ and relative displacement $\left(w_{\mathrm{Iu}}\right)$, as determined by CBBM equations, from specimens with a TL crack system.

\begin{tabular}{cccccccc}
\hline Ref & $\begin{array}{c}\boldsymbol{A}_{\mathbf{1}} \\
(\mathbf{N} / \mathbf{m m})\end{array}$ & $\begin{array}{c}\boldsymbol{A}_{\mathbf{2}} \\
(\mathbf{N} / \mathbf{m m})\end{array}$ & $\boldsymbol{p} \mathbf{( - )}$ & $\begin{array}{c}\boldsymbol{w}_{\mathbf{I} \mathbf{0}} \\
(\mathbf{m m})\end{array}$ & $\begin{array}{c}G_{\mathbf{l a w}, \mathbf{I}} \\
(\mathbf{N} / \mathbf{m m})\end{array}$ & $\begin{array}{c}\sigma_{\mathrm{I}, \mathbf{u}} \\
(\mathbf{M P a})\end{array}$ & $\begin{array}{c}\boldsymbol{w}_{\text {Iu }} \\
(\mathbf{m m})\end{array}$ \\
\hline 140-1-TL & 0.027 & 0.96 & 1.93 & 0.038 & 0.93 & 15.65 & 0.021 \\
140-2-TL & 0.012 & 0.94 & 1.83 & 0.056 & 0.92 & 10.31 & 0.029 \\
144-1-TL & 0.016 & 0.80 & 2.25 & 0.034 & 0.78 & 15.86 & 0.022 \\
161-1-TL & 0.023 & 1.16 & 1.92 & 0.056 & 1.13 & 12.92 & 0.031 \\
176-1-TL & 0.013 & 0.64 & 1.74 & 0.031 & 0.61 & 12.33 & 0.015 \\
176-2-TL & 0.007 & 0.73 & 1.73 & 0.043 & 0.70 & 10.31 & 0.020 \\
176-3-TL & 0.025 & 0.80 & 1.97 & 0.074 & 0.76 & 6.77 & 0.042 \\
189-1-TL & 0.015 & 0.87 & 1.70 & 0.063 & 0.85 & 8.35 & 0.029 \\
189-2-TL & 0.028 & 0.79 & 2.07 & 0.061 & 0.76 & 8.28 & 0.037 \\
192-1-TL & 0.023 & 0.45 & 2.26 & 0.036 & 0.43 & 8.35 & 0.024 \\
192-2-TL & 0.011 & 0.61 & 1.98 & 0.080 & 0.58 & 4.83 & 0.045 \\
192-3-TL & 0.007 & 0.42 & 2.26 & 0.042 & 0.41 & 6.78 & 0.027 \\
\hline Mean & 0.017 & 0.76 & 1.97 & 0.051 & 0.74 & 10.06 & 0.028 \\
SD & 0.008 & 0.21 & 0.21 & 0.016 & 0.21 & 3.52 & 0.009 \\
CoV (\%) & 44 & 28 & 10 & 32 & 28 & 35 & 32 \\
\hline
\end{tabular}

In these tables, the mean value of $A_{2}$ depicts an estimation of the critical strain energy release rate, $G_{\mathrm{Ic}}$, and it acquires the values of 0.78 and $0.76 \mathrm{~N} / \mathrm{mm}$ in the RL and TL crack propagation systems, 
respectively. These values are quite close to the mean ones obtained from the horizontal asymptote of the $R$-curves, that is $0.77 \mathrm{~N} / \mathrm{mm}$ in both propagation systems (see Tables 3 and 4 ).

The mean parameters of Tables 5 and 6 are used to build the mean experimental cohesive law in mode I that can be considered for Eucalyptus globulus in RL and TL crack systems. It is highlighted by a bold curve in Figure 10. As can be seen, the difference between both propagation systems is more pronounced in terms of cohesive law than it is for the other previously derived fracture parameters. Mean maximum stress in RL is approximately $50 \%$ higher than in the TL system. In general, the maximum stresses that were displayed by the RL specimens are reached with lower crack tip opening displacements than in TL.

The mean cohesive laws in mode I obtained for eucalyptus could be implemented in numerical cohesive zone models to simulate the development of the FPZ and crack growth, and thereby analyze the actual fracture behavior of a timber structure.

\section{Conclusions}

The cohesive laws in mode I of Eucalyptus globulus for RL and TL crack propagation systems were determined by means of DCB fracture tests. The CBBM data reduction method was applied to derive the strain energy release rate $\left(G_{I}\right)$ from the load-displacement curves when considering an equivalent crack length $\left(a_{\mathrm{eq}}\right)$ instead of the actual one, which would be difficult to measure. The $G_{\mathrm{I}}$ was correlated with the crack tip opening displacements measured by digital image correlation technique to obtain the cohesive laws.

The same $G_{\text {Ic }}$ value of $0.77 \mathrm{~N} / \mathrm{mm}$ was obtained for RL and TL crack propagation systems from the horizontal asymptote of the $R$-curves. The estimation of $G_{\mathrm{Ic}}$ from the logistic function parameters that was used to attain the cohesive law was also within the same range $(0.78$ and $0.76 \mathrm{~N} / \mathrm{mm}$ in RL and $\mathrm{TL}$, respectively).

The behavioral difference between the two crack propagation systems was more significantly displayed in the cohesive laws. In this sense, RL laws showed higher values of mean maximum cohesive stress at lower crack tip opening displacements in comparison with the TL system. The cohesive laws definition in both crack propagation systems makes it possible to implement them in numerical cohesive zone models to accurately simulate crack growth along the FPZ and quantify the actual fracture behavior of the timber structure in question, especially in elements and connections involving the possibility of brittle splitting failures.

The excellent mechanical properties added to the high fracture toughness shown in this study underline that Eucalyptus globulus L. is a hardwood species of great interest for structural design.

Author Contributions: Conceptualization, A.M.-M., A.J.L.-B., J.X. and J.M.; Methodology, J.X. and J.M.; Formal Analysis, A.M.-M. and A.J.L.-B.; Investigation, A.M.-M., A.J.L.-B., J.X. and J.M.; Resources, A.M.-M., A.J.L.-B., J.X. and J.M.; Writing-Original Draft Preparation, A.M.-M. and A.J.L.-B.; Writing-Review \& Editing, A.M.-M., A.J.L.-B., J.X. and J.M.; Supervision, J.X. and J.M.

Funding: This work was undertaken during a short-term scientific stay by the first and second authors at the University of Trás-os-Montes e Alto Douro, within the framework of the research project BIA 2015-64491-P Analysis of the stress relaxation in curved members and new joints solutions for timber Gridshells made out of Eucalyptus globulus, co-financed by the Ministry of Economy and Competitiveness of the Spanish Government and ERDF funds. The short-term stay was supported by a STSM Grant from COST Action FP1402 Basis of Structural Timber Design-from research to standards, ref. COST-STSM-ECOST-STSM-FP1402-091116-080058. This work is also supported by: European Investment Funds by FEDER/COMPETE/POCI-Operacional Competitiveness and Internacionalization Programme, under Project POCI-01-0145-FEDER-006958 and National Funds by FCT-Portuguese Foundation for Science and Technology, under the project UID/AGR/04033/2013.

Conflicts of Interest: The authors have no conflict of interest to declare.

\section{References}

1. Lara-Bocanegra, A.J.; Majano-Majano, A.; Crespo, J.; Guaita, M. Finger-jointed Eucalyptus globulus with 1C-PUR adhesive for high performance engineered laminated products. Constr. Build. Mater. 2017, 135, 529-537. [CrossRef] 
2. Lara-Bocanegra, A.J.; Majano-Majano, A.; Arriaga, F.; Guaita, M. Long-term bending stress relaxation in timber laths for the structural design of lattice shells. Constr. Build. Mater. 2018, 193, 565-575. [CrossRef]

3. LIGNUM-Nuevos Usos y Sistemas para la Madera Sólida de Eucalyptus globulus; ITC-20133059; FEDER Innterconecta Program, 2013.

4. XILOGRACILE-Tecnificación de la Cadena de Valor para el Desarrollo de Productos de altas Solicitaciones Técnicas con Madera de Eucalipto; ITC-20151124; FEDER Innterconecta Program, 2015.

5. De Moura, F.S.F.; Dourado, N. Wood Fracture Characterization, 1st ed.; CRC Press Taylor \& Francis Group: Boca Raton, FL, USA, 2018; ISBN 9780815364719.

6. Odounga, B.; Moutou Pitti, R.; Toussaint, E.; Grédiac, M. Mode I fracture of tropical woods using grid method. Theor. Appl. Fract. Mech. 2018, 95, 1-17. [CrossRef]

7. EN 1995-1-1:2016. Eurocode 5: Design of Timber Structures. Part 1-1: General. Common Rules and Rules for Buildings; The Spanish Association for Standardization and Certification (AENOR): Madrid, Spain, 2016.

8. Van der Put, T.A.C.M.; Leijten, A.J.M. Evaluation of perpendicular to grain failure of beams caused by concentrated loads of joints. In Proceedings of the International Council for Research and Innovation in Building and Construction, Delft, The Netherlands, 28-30 August 2000.

9. Jensen, J.L.; Girhammar, U.A.; Quenneville, P.; Källsner, B. Splitting of beams loaded perpendicular to grain by connections-simple fracture mechanics models. In Proceedings of the World Conference on Timber Engineering (WCTE), Auckland, New Zeland, 15-19 July 2012.

10. Caldeira, T.V.P.; Dourado, N.; de Jesus, A.M.P.; de Moura, M.F.S.F.; Morais, J.J.L. Quasi-static behavior of momento-carrying steel-wood doweled joints. Constr. Build. Mater. 2014, 53, 439-447. [CrossRef]

11. Santos, C.L.; Morais, J.J.L.; de Jesus, A.M.P. Mechanical behaviour of wood T-joints. experimental and numerical investigation. Frattura ed Integrità Strutturale 2015, 31, 23-37. [CrossRef]

12. De Moura, M.F.S.F.; Silva, M.A.L.; de Morais, A.B.; Morais, J.J.L. Equivalent crack based mode II fracture characterization of wood. Eng. Fract. Mech. 2006, 73, 978-993. [CrossRef]

13. Barenblatt, G.I. The Mathematical Theory of Equilibrium Cracks in Brittle Fracture. Adv. Appl. Mech. 1962, 7, 55-129. [CrossRef]

14. Dugdale, D. Yielding of steel sheets containing slits. J. Mech. Phys. Solids 1960, 8, 100-104. [CrossRef]

15. Boström, L. The stress-displacement relation of wood perpendicular to the grain. Part 1. Experimental determination of the stress-strain relation. Wood Sci. Technol. 1994, 28, 309-317. [CrossRef]

16. Blal, N.; Daridon, L.; Monerie, Y.; Pagano, S. Artificial compliance inherent to the intrinsic cohesive zone models: Criteria and application to planar meses. Int. J. Fract. 2012, 178, 71-83. [CrossRef]

17. Wang, Y.; Waisman, H. Progressive delamination analysis of composite materials using XFEM and a discrete damage model. Comput. Mech. 2015, 55, 1-26. [CrossRef]

18. Pereira, F.A.M.; de Moura, M.F.S.F.; Dourado, N.; Morais, J.J.L.; Xavier, J.; Dias, M.I.R. Direct and inverse methods applied to the determination of mode I cohesive law of bovine cortical bone using the DCB test. Int. J. Solids Struct. 2017, 128, 210-220. [CrossRef]

19. Dourado, N.; Morel, S.; de Moura, M.; Valentin, G.; Morais, J. Comparison of fracture properties of two wood species through cohesive crack simulations. Compos. Part A Appl. Sci. Manuf. 2008, 39, 415-427. [CrossRef]

20. De Moura, M.F.S.F.; Morais, J.J.L.; Dourado, N. A new data reduction scheme for mode I wood fracture characterization using the double cantilever beam test. Eng. Fract. Mech. 2008, 75, 3852-3865. [CrossRef]

21. Volokh, K.Y. Comparison between cohesive zone models. Int. J. Numer. Methods Biol. 2004, 845-856. [CrossRef]

22. Fernberg, S.P.; Berglund, L.A. Bridging law and toughness characterization of CSM and SMC composites. Compos. Sci. Technol. 2001, 61, 2445-2454. [CrossRef]

23. EN 408:2011. Timber Structures—Structural Timber and Glued Laminated Timber-Determination of Some Physical and Mechanical Properties; The Spanish Association for Standardization and Certification (AENOR): Madrid, Spain, 2011.

24. Crespo, J.; Aira, J.R.; Vázquez, C.; Guaita, M. Comparative analysis of the elastic constants measured via conventional, ultrasound, and 3-D Digital Image Correlation methods in Eucalyptus globulus. Bioresources 2017, 12, 3728-3743. [CrossRef]

25. Xavier, J.; Morais, J.; Dourado, N.; de Moura, M.F.S.F. Measurement of Mode I and mode II fracture properties of wood-bonded joints. J. Adhes. Sci. Technol. 2011, 25, 2881-2895. [CrossRef] 
26. Xavier, J.; Oliveira, M.; Monteiro, P.; Morais, J.J.L.; de Moura, M.F.S.F. Direct evaluation of cohesive law in Mode I of Pinus pinaster by Digital Image Correlation. Exp. Mech. 2014, 54, 829-840. [CrossRef]

27. Williams, J. The fracture mechanics of delamination tests. J. Strain Anal. 1989, 24, 207-214. [CrossRef]

28. Irwin, G.R.; Kies, J.A. Critical energy rate analysis of fracture strength. Weld Res. Suppl. 1952, 33, $193-198$.

29. Xavier, J.; Oliveira, M.; Morais, J.J.L.; de Moura, M.F.S.F. Determining mode II cohesive law of Pinus pinaster by combining the end-notched flexure test with digital image correlation. Constr. Build. Mater. 2014, 71, 109-115. [CrossRef]

30. Silva, F.G.A.; Morais, J.J.L.; Dourado, N.; Xavier, J.; Pereira, F.A.M.; de Moura, M.F.S.F. Determination of cohesive laws in wood bonded joints under mode II loading using the ENF test. Int. J. Adhes. Adhes. 2014, 51, 54-61. [CrossRef]

31. GOM mbH. ARAMIS Commercial Software; ARAMIS 6.0.2; GOM mbH: Braunschweig, Germany, 2007.

32. Xavier, J.; de Jesus, A.M.P.; Morais, J.J.L.; Pinto, J.M.T. Stereovision measurements on evaluating the modulus of elasticity of wood by compression tests parallel to the grain. Constr. Build. Mater. 2012, 26, 207-215. [CrossRef]

33. Sousa, A.M.R.; Xavier, J.; Morais, J.J.L.; Filipe, V.M.J.; Vaz, M. Processing discontinuous displacement fields by a spatio-temporal derivative technique. Opt. Laser Eng. 2011, 49, 1402-1412. [CrossRef]

34. Xavier, J.; Sousa, A.M.R.; Morais, J.J.L.; Filipe, V.M.J.; Vaz, M. Measuring displacement fields by cross-correlation and a differential technique: Experimental validation. Opt. Eng. 2012, 51, 043602. [CrossRef]

35. Withers, P.J. Fracture mechanics by three-dimensional crack-tip synchrotron X-ray microscopy. Philos. Trand. R. Soc. A 2015, 373, 2036. [CrossRef]

36. Wu, X.; Schlangen, E.; van der Zwaag, S. Linking crack tip morphology to tear toughness of hot rolled AA7050 alloys using X-ray computed tomography. Adv. Eng. Mater. 2012, 14, 449-456. [CrossRef]

37. Tran, H.; Doumalin, P.; Delisee, C.; Dupre, J.C.; Malvestio, J.; Germaneau, A. 3D mechanical analysis of low-density wood-based fiberboards by X-ray microcomputed tomography and Digital Volume Correlation. J. Mater. Sci. 2013, 48, 3198-3212. [CrossRef]

38. Forsberg, F.; Sjödahl, M.; Mooser, R.; Hack, E.; Wyss, P. Full Three-Dimensional Strain Measurements on Wood Exposed to Three-Point Bending: Analysis by Use of Digital Volume Correlation Applied to Synchrotron Radiation Micro-Computed Tomography Image Data. Strain 2010, 46, 47-60. [CrossRef]

39. Lachambre, J.; Réthoré, J.; Weck, A.; Buffiere, J.-Y. Extraction of stress intensity factors for 3D small fatigue cracks using digital volume correlation and X-ray tomography. Int. J. Fatigue 2015, 71, 3-10. [CrossRef]

40. Majano-Majano, A.; Hughes, M.; Fernandez-Cabo, J.L. The fracture toughness and properties of thermally modified beech and ash at different moisture contents. Wood Sci. Technol. 2012, 46, 5-21. [CrossRef] 